\title{
Student Beliefs as Barriers to Articulation
}

\author{
Debbie Meharg \\ The School of Computing \\ Edinburgh Napier University \\ Edinburgh, UK \\ D.Meharg@napier.ac.uk
}

\author{
Stephanie Craighill \\ The School of Computing \\ Edinburgh Napier University \\ Edinburgh, UK \\ S.Craighill@napier.ac.uk
}

\begin{abstract}
Eccles et al.'s 'Expectancy-Value Model of Achievement Motivation' (2000) states that 'an individual's choice, persistence, and performance can be explained by their beliefs about how well they will do on the activity and the extent to which they value the activity' [1]. This paper employs Eccles et al.'s theoretical framework to identify performance barriers and facilitators for Scottish college students who have just opted to articulate to Higher Education (HE). Using this model to understand student ability beliefs and motivations at the beginning of the articulation process identifies potential performance challenges and informs strategies to improve the transition experience from Further to Higher Education.
\end{abstract}

At three Scottish colleges focus groups were conducted with students who have selected an articulation route to HE. Discussion focused around a number of theoretical strands inherent to the Expectancy-Value Model, such as ability beliefs and motivation components. These components were used to determine student potential to perform and persist with HE. Research conclusions suggest that the sample of college students has largely positive ability beliefs and possesses an optimistic perception of success in $\mathrm{HE}$ but identify a number of challenges. Research outcomes inform approaches to enhance the transition experience of college students to Higher Education.

Keywords- Ability Beliefs; Barriers; Further Education; Higher Education; Motivation; Performance; Persistence

\section{INTRODUCTION}

Eccles et al. (2002) argue that it is difficult if not impossible to understand students' motivation without understanding the contexts they are experiencing' [2]. This paper examines the ability beliefs and motivation of college students in the context of Eccles et al.'s 'Expectancy-Value Model' during articulation by examining performance barriers and the strategies implemented to improve the transition experience.

This research draws on the Associate Student Project as a longitudinal research programme which focuses on articulating students from Further Education (FE) partner institutions to adjacent courses at Edinburgh Napier University in The School of Computing. Research explores the relationship between ability beliefs and motivations as barriers for direct entrants. This work is particularly relevant as the Scottish Government aims to remove barriers to widening access and participation in higher education [3]. Research findings can inform best practice approach at $\mathrm{FE}$ and $\mathrm{HE}$ institutions, enhance the experience of articulating students, guide policy makers and aid knowledge transfer. While this paper has implications for the wider international context its main focus will be the Scottish education system.

This paper begins by discussing widening participation as a general concept, before proceeding to determine how Eccles et al.'s model can be applied to the ability beliefs and motivations of articulating students as markers for success in the HE context. Using this model as a framework, focus groups with college students at the beginning of their HE journey were used to identify perceived barriers, beliefs and motivations which were used to inform strategies in academic practice.

\section{CONTEXT}

For 10 years the Scottish Funding Council (SFC) [4] have supported articulation of students with HN's to degree study as a method of widening participation and increasing rates of access to university. Scotland, however, continues to have the poorest rate of access to university in the whole of the UK [5]. In order to progress this initiative in 2013 the SFC introduced additional funding and set ambitious targets for universities to support additional places. These additionally funded students are known as Associate Students and form the direct entrant cohort coming into the 3 rd year of degree study on a 4 year programme $(2+2$ model). For the academic year 2013/14 Edinburgh Napier University was awarded funding from the SFC for an additional 107 places for students starting their programmes in college and articulating to university for third and fourth year. Targeted learning opportunities were designed to enhance student progression and attainment by addressing barriers to success in the very different HE environment.

Scottish Government figures state that in the year 2010/11 a total of 2,844 Scottish-domiciled students entered with advanced standing [6]. There are many barriers and beliefs which hinder student success at university and removing these with interventions and key facts and figures is a major starting point. In terms of the bigger picture widening participation has significance for society as whole and increasing education standards within the population leads to a healthier society who are more engaged in democratic processes and more productive overall [7].

\section{APPlying ECCLES ET AL.'S 'EXPECTANCY MODEL OF ACHIEVEMENT MOTIVATION’ (2000)}

Eccles et al.'s 'Expectancy Model of Achievement Motivation' (2000) is an appropriate framework to evaluate the propensity for academic success before a student has made the 
transition from college to university. Eccles et al.'s model has evolved from related theories such as Bandura's (1997) 'SelfEfficacy Theory' [8], which makes use of expectancy and efficacy beliefs to forecast achievement capabilities, but is most closely related to Aktinson's (1957) 'Expectancy-Value Theories' which link achievement performance, persistence and choice [9].

Adapting Eccles et al.'s model, Figure 1, to incorporate the perceptions, beliefs and experiences of direct entrants during transition allows us to consider the interventions and their implications in a visual context. This paper appropriates two principles that are central to Eccles et al.'s framework: expectancies and attainment value. This model defines the term 'expectancies' as an individual's ability beliefs or perception of their competence, potential to perform and probability of success or failure. While 'attainment value', or motivation, is classified as an individual's perception of the importance of the activity. Eccles et al. posit that together expectancies and attainment value 'directly influence' an individual's 'performance, persistence and choice' [10]. This model is, therefore, useful in determining potential retention and performance rates, and selection of courses, by students in a range of learning environments.

Eccles et al.'s 'Expectancy Model of Achievement Motivation' (2000) has been applied widely in a range of international primary and secondary school contexts. For example Xiang et al. (2002) [11] make use of this model to assess children's motivation during physical education, while Wolters et al. (1998) [12] apply it to student motivation in Maths, English and Social Studies. However, although, some work such as Richardson et al.'s study exploring motivations across three Australian Universities does apply Eccles et al.'s model to Higher Education learning, these studies are in the minority and the model is yet to be applied to articulating students.

This paper makes an original contribution by applying Eccles et al.'s theory in a new context and can provide real insight into the potential for college students to perform at university. If a student has positive ability beliefs, i.e. they feel they will succeed at university, and place value on the importance of achieving in this new learning context they are more likely to choose to articulate and, subsequently, persist and perform during their studies.

\section{METHODOLOGY}

This paper applies Eccles et al.'s model to college students, studying at three Scottish institutions, who have completed their application forms and opted to articulate to university study. The 'Expectancy Model of Achievement Motivation' suggests that if a student values HE study and believes they can achieve at university they will succeed. At each of the three Colleges focus groups were conducted, involving six to eight participants, to determine student performance potential in the university environment within the Eccles et al.'s framework.

As this is a perception based study, which asks students to assess their motivations and commitment to HE study, appropriating quantitative methods of data collection would be unfeasible. However, focus groups, typically associated with 'socially orientated research', are a useful research approach when gathering the views of college students at the beginning of the articulation process [13]. In the context of this study, this chosen methodology has many advantages. While interviews would contribute in-depth insight into the individual views of those students planning to articulate, focus groups allow us to gather rich perspective on the collective, localised views of the target market [14]. Unlike other forms of social research, which are more observational in nature, the focus group format allows for a moderator to guide the nature of discussion by keeping the conversation focused and encouraging engagement from all participants. Krueger \& Casey (2000) propose, therefore, that this research approach is a dynamic process, which is flexible not standardised, allowing the moderator to follow-up on relevant points of discussion [15].

However, while there are a range of benefits to using focus groups to determine articulating students' motivations and ability beliefs, the method does have some recognised limitations. While the localised nature of the sample generates a collective perspective, the specificity of findings means that generalisation of outcomes can be challenging [16]. Additionally, the nature of the dialogue is dependent upon the individuals that take part and one strong character can dominate over the group. Moreover, the public nature of the discussion is less conducive to open honest communication about sensitive topics. Although, these limitations were taken in to account, it was thought that the skill of the moderator in creating a comfortable and inclusive environment, combined with the rich insight gained from focus group discussions, would offset any methodological challenges.

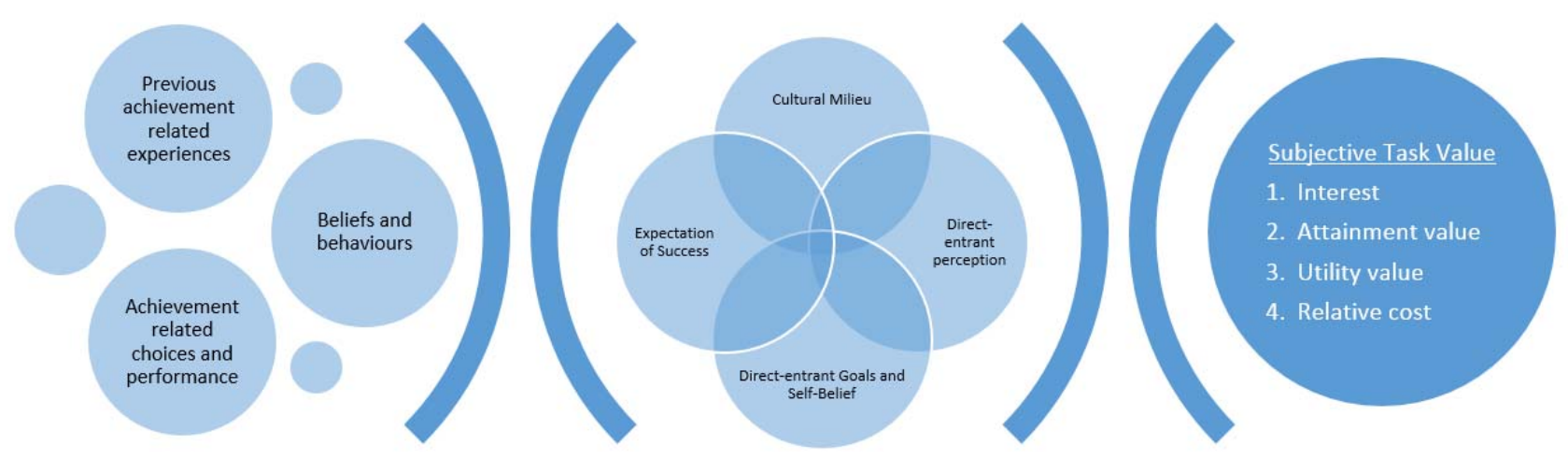

Figure 1.

Based on Eccles et al.'s 'Expectancy Model of Achievement Motivation' (2000) and its application to direct entrants. 
At all times, ethical considerations were a priority and participants were fully informed about the aims and outcomes of the focus group, informed consent was obtained, and colleges and student contributions were anonymised to protect the confidentiality of all participants in the study. Coding was employed as a grounded and systematic data reduction technique for synthesizing, or bringing together, insight generated from all three focus groups. The raw data was coded, according to the two themes, ability beliefs and motivations, with a view to determining emerging patterns and ideas [17]. The coded textual data revealed that focus groups were an appropriate means of establishing student motivations and ability beliefs, to forecast potential performance and persistence at university, at the beginning the articulation process.

\section{FINDINGS}

During each focus group students were, firstly, asked to discuss the reasons why they had chosen to articulate, i.e. the motivation behind their decision, and, secondly, to explore any negative or positive beliefs they held about how they would perform in the university environment. According to Eccles et al.'s model these two principles combined account for success and perseverance in any task and, in theory, students with positive ability beliefs and a strong understanding of the reasons they are choosing to articulate will fare better in the university context.

\section{A. Attainment Value: Student Motivations for Choosing to Articulate}

Students across all three focus groups displayed a strong understanding of the reason why they were applying for university. The majority of respondents felt that gaining a degree qualification would enhance their career prospects. One student proposes that 'With most jobs you do need a degree'. After graduating from university, focus group participants were also keen to pursue apprenticeships and further study to Masters level but the general consensus is encapsulated by one student who claims, 'the point of going to university is to differentiate yourself from others'. However, a small crosssection of participants were less clear about their reasons for articulating and applied to university as it felt like the next logical step which is a less positive and decisive motivation for committing to a further two years study.

\section{B. Negative and Positive Ability Beliefs}

While, in the main, students had well-considered reasons for applying to university they also perceived a number of academic and social barriers which could impede their success in this new learning context. The shift in learning culture was a commonly cited obstacle to effective academic integration, one student comments that 'the shift in atmosphere concerns me, we all went from High School to college and then to university - three complete shifts in atmosphere and the way of learning. I hope we can handle it'. This 'shift in atmosphere' is characterised by two main concerns: an increase in independent learning and a more demanding workload. University learning is perceived to be a more autonomous process and focus group participants were apprehensive about access to academic support. One participant comments, 'there will be a lack of being able to get advice from the lecturer...that worries me'. Negative ability beliefs were, also, raised about curriculum matching and whether the college syllabus would adequately prepare direct entrants for successful academic transition into the third year at university. 'I think at first we will undoubtedly struggle', states one individual, 'there are bound to be things that the first and second years did that we haven't done at college'.

Aside from academic concerns, students were conscious of social barriers that might affect integration into an already established peer group of third year university students. One individual suggests, "people that have been going for years might have their little cliques, so if you're going into the group you might feel like an outsider'. However, some issues raised were more practical in nature and related to travel, timetabling and social care issues including childcare and support for disability. One focus group participant discusses the implications of class times, 'Not knowing means I can't plan ahead which could affect my performance'.

Although, each focus group revealed a number of negative beliefs that might impact on a student's ability to perform and persist in the university environment, the majority of students when asked how they would fare in this new learning context were positive. One student proposes that, 'you wouldn't put us into third year if you didn't think we were capable', while another determines that, 'I think we have been given the opportunity to do well and I don't see why we would suddenly underperform after the transition'. In the main, students planning to articulate held positive ability beliefs but it is clear, however, that they also perceive many barriers to their success at university. The next section discusses how these negative ability beliefs, relating to academic and social integration, have been used to inform strategies to enhance the transition experience from college to university, breaking down the barriers to HE education.

\section{IMPLEMENTATION}

The additional funding provided by the SFC has allowed the Associate Student Project to focus on a number of initiatives to support student articulation, primarily student preparedness, both socially and in terms of the academic curriculum. In the 'Expectancy-Value Model' ability beliefs are conceived as broad beliefs about competence in a given domain, in contrast to one's expectancies for success on a specific upcoming task. A number of initiatives have been implemented to impact on the Associate Students previous achievement related experiences and ensure that their goals and self-belief point towards a positive expectation of success.

Facebook and Twitter have been adopted to engage with Associate Students and direct entrants whilst studying at partner colleges with a view to enforcing their ability belief through peer support and general information about university life [18]. This online interaction helps to create a sense of community in what would otherwise be a disparate group where continuing and articulating students can be predisposed to segregation, finding it difficult to blend in with the existing student cohort. A positive marketing message and presence has 
been developed, specifically posters, leaflets and website content to ensure students, staff and importantly parents are aware of the significance of the project and of the benefits that await those who make the transition to university. By raising the profile of articulation the perception and expectation of success for direct entrants will increase. As the Associate Student Project is nearing the end of its first year of implementation, student stories and video diaries are currently being captured to share with future articulating students. This will impact on their ability beliefs by building a positive image of articulation amongst the college students and increasing their expectation of success at degree level.

All Associate Students have matriculated at university and consequently are regarded as HE students from their first day at college. This approach not only increases the visibility of Associate Students and allows them the opportunity to integrate with other university students on campus in libraries, the student union and through other facilities, but also helps in the formation of the university student identity and builds their social standing [19]. Attendance at university open days informs perception and allows the student to adjust their expectations for continued study at degree level. By talking to other students throughout the day they will align their attainment value and recognise that HE study is within their capability by engaging with direct entrants about their previous experiences and successes. Any negative ability beliefs can be dispelled through discussions with current and past students enabling direct entrants to visualise the task, positively impacting on their goals and self-belief, and increasing the expectation of success. College students were invited to attend drop-in lectures and guest lectures facilitating the opportunity to experience first-hand the culture of learning within an $\mathrm{HE}$ institution removing this barrier and building ability beliefs. These strategies were introduced during the initial stages of the Associate Student Project and are the subject of ongoing evaluation and development.

\section{SCOPE FOR FUTURE WORK}

The findings presented in this paper represent a small dimension of The Associate Student Project, at Edinburgh Napier University, examining best practice in articulation. All research that is undertaken, therefore, has a dual purpose - to add to the body of knowledge on articulation but, additionally, to inform strategies for academic best practice. This study appropriates Eccles et al.'s 'Expectancy Model of Achievement Motivation' (2000) to forecast the potential for students to succeed in the university context after articulating from college. While focus group outcomes largely suggest that the sample of students would persist and perform well in the HE environment, only a longitudinal study will determine if this was an accurate prediction. It is, therefore, essential that focus group participants be monitored throughout their articulation journey to identify whether indicators for success within Eccles et al.'s model were successful predictors of persistence and performance at university. These can be measured using retention rates and academic grades as markers. Additionally, it would be useful to triangulate focus group findings by conducting in-depth interviews and anonymous questionnaires with those who took part in the study. While the focus group method generated some rich insights, a small-scale pilot study using anonymous questionnaires, identified that emotive topics are not always openly discussed in a public forum such as a focus group. Follow-up questionnaires would highlight any methodological issues or strengthen our research conclusions.

Additionally, as discussed, research outcomes have been actioned, and implemented, in academic practice. The potential challenges raised by those students at the start of their articulation journey have informed early intervention strategies to identify, and overcome, any barriers to articulation at 'PreEntry level'. The Associate Student Project team at Edinburgh Napier University is working hard to determine and implement best practice in articulation and, therefore, there is considerable scope for future work within this field.

\section{REFERENCES}

[1] Eccles, J.S., \& Wigfield, A. (2000). Expectancy-value theory of achievement motivation. Contemporary Educational Psychology, 25, 116-119.

[2] Scottish Government (a) (2012). Post-16 transitions, Policy and practice framework: Supporting all young people to participate in post-16 learning, training or work.

[3] Scottish Funding Council (2013). Guidance: Additional articulation places scheme for partnership between colleges and universities.

[4] Eccles, J.S. \& Wigfield, A. (2002). 'Motivational beliefs, values, and goals'. Annual Review of Psychology. Vol. 53: 109-132.

[5] NUS Scotland. (2014). 'Unlocking Scotland's Potential: Promoting Fairer Access to Higher Education'. Available at: http://www.nus.org.uk/Documents/NUS\%20Scotland/Unlocking\%20Sc otland's\%20Potential.pdf

[6] NUS Scotland. (2014). 'Unlocking Scotland's Potential: Promoting Fairer Access to Higher Education'. Available at: http://www.nus.org.uk/Documents/NUS\%20Scotland/Unlocking\%20Sc otland's\%20Potential.pdf

[7] NUS Scotland. (2014). 'Unlocking Scotland's Potential: Promoting Fairer Access to Higher Education'. Available at: http://www.nus.org.uk/Documents/NUS\%20Scotland/Unlocking\%20Sc otland's\%20Potential.pdf

[8] Bandura, A. (1997). Self-efficacy: The exercise of control. New York: Freeman.

[9] Atkinson, J. W. (1957). Motivational determinants of risk taking behavior. Psychol. Rev. 64: 359 -372.

[10] Eccles, J.S. \& Wigfield, A. (2002). 'Motivational beliefs, values, and goals'. Annual Review of Psychology. Vol. 53: 109-132. 128 p 128

[11] Xiang, P., McBride, R., Guan, J., \& Solmon, M.A. (2003). Children's motivation in elementary physical education: An expectancy-value model of achievement choice. Research Quarterly for Sport and Exercise, 74, 25-35.

[12] Wolters, C. A. (1998). Self-regulated Learning and College Students' Regulation of Motivation. Journal of Educational Psychology, 90, 224235.

[13] Fern, E.F. (2001). Advanced Focus Group Research. Thousand Oaks, Calif: Sage.

[14] Bryman, A. (2012). Social Research Methods, Oxford: Oxford University Press.

[15] Kruger, R.A. (1994). Focus groups: a practical guide for applied research, 2d ed. Thousand Oaks, CA: Sage Publications.

[16] Pickering, M. (2008). Research Methods in Cultural Studies: Research Methods for Cultural Studies. Edinburgh: Edinburgh University Press.

[17] Basit, T. (2003). 'Manual or electronic? The role of coding in qualitative data analysis' Educational Research, 45 (2).

[18] Jenkins, G. Lyons, K. Bridgstock, R. and Carr, L. (2012). Like our page - using Facebook to support first year students in their transition to 
higher education. A practice report. The International Journal of the First Year in Higher Education, Vol. 3 (2), pp 65-72.

[19] Martin, L. Spolander, G. Ali, I. and Maas, B. (2014). The evolution of student identity: A case of caveat emptor, Journal of Further and Higher Education, Vol. 38 (2), pp. $200-210$.

[20] Christie, H. Barron, P \& D'Annunzio-Green, N. (2013). Direct entrants in transition: becoming independent learners, Studies in Higher Education, Vol. 38 (4), pp. 623-637.

[21] Booth, A (2001). Developing History Students' Skills in the Transition to University, Teaching in Higher Education, Vol. 6 (4), pp, 487-503.

[22] Wenger, E. (1989). Communities of Practice: Learning, Meaning and Identity. Cambridge: Cambridge University Press. 